\title{
Effects of gamma radiation on nanocomposite films of polycaprolactone with modified MCM-48
}

\author{
Marcos Vinícius Paula1* (D), Leandro Araújo de Azevedo² (D), Ivo Diego de Lima Silva ${ }^{3}$ (D), \\ Glória Maria Vinhas ${ }^{3}$ (D), Severino Alves Junior ${ }^{2}$ (i)
}

${ }^{1}$ Faculdade de Engenharia de Materiais, Universidade Federal do Pará - UFPA, Campus Ananindeua,
Belém, Pará, Brasil

2Laboratório de Terras Raras, Departamento de Química Fundamental, Universidade Federal de Pernambuco - UFPE, Recife, Pernambuco, Brasil

${ }^{3}$ Laboratório de Materiais Poliméricos e Caracterizacão, Departamento de Engenharia Química, Universidade Federal de Pernambuco - UFPE, Recife, Pernambuco, Brasil

*mpaula@ufpa.br

\begin{abstract}
The aim of this investigation was to assess the effects of gamma radiation on nanocomposite films (NC films) formed by PCL (polycaprolactone) with MCM-48 nanoparticles (PCL/MCM-48) and PCL with MCM-48 NPs modified with (3-aminopropyl)triethoxysilane (APTES) (PCL/MCM-48- $\mathrm{NH}_{2}$ ). The nanocomposite films were obtained using the solvent casting method. After preparing the films, they were irradiated at $25 \mathrm{kGy}$ in the presence of air and analyzed by X-ray diffraction (XRD), Fourier transform infrared spectroscopy (FT-IR), differential scanning calorimetry (DSC), thermogravimetric analysis (TGA), and scanning electron microscopy (SEM), transmission electronic microscopy (TEM), as well as for their mechanical properties. The exposure of NC films to gamma radiation at $25 \mathrm{kGy}$ did not cause major changes in either thermal or mechanical properties such as tensile strength and modulus of elasticity. The results revealed that gamma radiation was a successful choice for the sterilization of these materials.
\end{abstract}

Keywords: gamma radiation, MCM-48, mechanical properties, polycaprolactone.

How to cite: Paula, M. V., Azevedo, L. A., Silva, I. D. L., Vinhas, G. M., \& Alves Junior, S. (2021). Effects of gamma radiation on nanocomposite films of polycaprolactone with modified MCM-48. Polimeros: Ciência e Tecnologia, 31(3), e2021031. https://doi.org/10.1590/0104-1428.20210044

\section{Introduction}

Polycaprolactone (PCL) is a synthetic polymer formed of hexanoate units linked by ester linkages ${ }^{[1,2]}$. It is a hydrophobic, semi-crystalline polymer, being biocompatible and biodegradable ${ }^{[3-5]}$. PCL is a biocompatible polymer ${ }^{[6]}$, which is interesting for its use for implants ${ }^{[7]}$, controlled drug release systems ${ }^{[8]}$, scaffolds ${ }^{[9]}$ and in food packaging ${ }^{[10]}$. PCL is degraded by microorganisms and enzymes ${ }^{[2,11]}$. This degradation may take years, depending on its molecular mass, crystallinity content and degradation conditions ${ }^{[2]}$. In the human body, PCL is degraded via hydrolysis of the ester bonds and eliminated from the body through the citric acid cycle ${ }^{[2]}$. For some applications, PCL does not have satisfactory thermomechanical properties ${ }^{[12]}$. One way to solve this lack of satisfactory thermomechanical properties is to add nanomaterials to the PCL, producing a final material called a nanocomposite ${ }^{[13,14]}$. Nanometric materials have a high surface area and volume, presenting distinct chemical and physical properties when they are on a micro or macro scale $^{[15]}$. Nanosized particles known as nanoparticles (NPs) may also be used as fillers ${ }^{[16,17]}$. However, these materials have a high tendency to aggregate, which may render the dispersion in the polymer unfeasible, compromising the

anticipated final properties of the material ${ }^{[18]}$. This dispersion, however, can be improved by changing the surface of the NPs from surfactant molecules or other modifiers by stabilizing and improving the dispersion of the NPs in the matrix, which provides strong repulsion between the $\mathrm{NPS}^{[15]}$. Ordered mesoporous silica are among the materials that have nanometric dimensions that can be added to the polymers. They were first synthesized in 1992 through the M41S ${ }^{[19]}$ family of materials and used to promote the increase of thermal stability of polymers ${ }^{[20]}$. They have porous ordered structures of silicon oxide $\left(\mathrm{SiO}_{2}\right)^{[21]}$, involving the silanols $(\mathrm{Si}-\mathrm{OH})$ groups $^{[22]}$. One of the most popular members of this family is the MCM-48 ${ }^{[19]}$. The nanoparticles of MCM-48 (MCM-48 NPs) have a cubic structure indexed in the spatial group Ia3d with 2 interpenetrating networks , biocompatibility and high thermal stability, which justifies their use as a thermal stabilizing agent for polymers ${ }^{[19,20,21,23]}$. Some authors attribute this effect to the mechanism of radical scavenging by MCM-48 NPs during thermal degradation ${ }^{[20]}$. This indicates a promising use of MCM-48 NPs to form NCs with PCL to obtain materials with better thermomechanical properties. Lopez-Figueras and co-workers, modified the 
surface of MCM-41 with N-[3-trimethoxysilyl) propyl] ethylenediamine (EPTES), to increase the dispersibility of MCM-41 in the PCL ${ }^{[12]}$. The composites obtained with the modified silica had better thermal properties than the polymer, besides showing greater dispersion of the NPs in the PCL. The improvement in thermal properties and dispersibility was attributed to surface modification with EPTES and the performance of NPs as a barrier. Mallakpour and Khani, using the solvent evaporation method, produced films of NCs between PCL and amorphous $\mathrm{SiO}_{2}$ nanoparticles modified with vitamin B1. The films exhibited better thermomechanical properties than PCL, in addition to exhibiting in vitro bioactivity with the formation of hydroxyapatite, which reveals the potential of the materials obtained to be used in bone tissue engineering ${ }^{[24]}$.

Most of the academic and manufacturing interest in PCL materials involves the use of these materials in medical applications such as drug delivery ${ }^{[25]}$, implants ${ }^{[26]}$, tissue engineering ${ }^{[27]}$ and in food packaging ${ }^{[28]}$. For these applications, the materials need to be sterilized to kill microorganisms such as fungi, bacteria and viruses ${ }^{[29]}$. The standard procedure adopted for sterilization is the exposure of these materials to gamma radiation at $25 \mathrm{kGy}^{[30]}$. This exposure kills microorganisms that can modify their chemical and physical properties, due to the origin of effects such as scission and cross-linking of polymer chains ${ }^{[30]}$.

Thus, this study sought an innovative means to identify the effects of gamma radiation at $25 \mathrm{kGy}$ on the structural, thermal and mechanical properties of NCs formed by PCL with MCM-48 NPs modified with APTES. The choice of dose at $25 \mathrm{kGy}$ was established based on the concept of verification dose maximum $\left(\mathrm{VD}_{\max }\right)^{[31]}$, to achieve an sterility assurance level (SAL) of $10^{-6}$ or better for bacteria. However for virus sterilization doses greater than $25 \mathrm{kGy}$ are required, but the use of these doses is beyond the scope of our investigation ${ }^{[31]}$. The films formed by PCL with $0.5 \%$ modified and unmodified MCM- 48 NPs were produced by the solvent casting method and exposed to gamma radiation at $25 \mathrm{kGy}$ in the presence of air.

\section{Materials and Methods}

\subsection{Materials}

All the reagents used were analytical grade and used as received. Tetraethylorthosilicate (98\%), cetyltrimethylammonium bromide (98\%), a non-ionic detergent (Pluronic ${ }^{\circledR}$ F-127), 3-(Aminopropyl)triethoxysilane and ammonium hydroxide were acquired from Sigma Aldrich. Chloroform, ethanol, toluene and were purchased from Dinâmica.

\subsection{Preparation of MCM-48 nanoparticles}

The MCM-48 NPs were obtained according to the literature ${ }^{[2]}$ with some modifications. To obtain MCM$48,0.5 \mathrm{~g}$ of cetyltrimethylammonium bromide, $2.05 \mathrm{~g}$ of F127 (Pluronic ${ }^{\circledR}$ F-127) was diluted in $96 \mathrm{~mL}$ of distilled water, then $43 \mathrm{~mL}$ of ethanol was added, together with $10.05 \mathrm{~g}$ of $29 \%$ ammonium hydroxide solution. The mixture was stirred until homogeneous, followed by addition of 1.8 grams of tetraethylorthosilicate. This mixture was stirred for 10 minutes and kept standing for 12 hours at room temperature. Thereafter, the mixture was centrifuged at $6000 \mathrm{rpm}$ for 30 minutes. A white solid was obtained which was then washed with distilled water and centrifuged again, under the same conditions as above, then dried at $70^{\circ} \mathrm{C}$ for 12 hours. This solid was added to the Teflon reactor with $8.5 \mathrm{~mL}$ of distilled water, subjected in a sealed system to a temperature of $140^{\circ} \mathrm{C}$ for 48 hours, with heating and cooling rates of $10^{\circ} \mathrm{C} \mathrm{min}^{-1}$ in a programmable oven. After this step, the solid obtained was heated at $550{ }^{\circ} \mathrm{C}$ for 4 hours in a programmable oven, with alterations in heating and cooling at a rate of $10^{\circ} \mathrm{C} \mathrm{m^{-1 }}$.

\subsection{Functionalization of MCM-48 nanoparticles}

The MCM-48- $\mathrm{NH}_{2}$ NPs were synthesized according to the literature, with some modifications ${ }^{[32]}$. Basically $3 \mathrm{~mL}$ of APTES was added dropwise to a suspension formed by 1 gram of MCM-48 NPs and $30 \mathrm{~mL}$ of dry toluene under nitrogen atmosphere. The mixture obtained was refluxed for 24 hours. Then the suspension was filtered and rinsed with ethanol. The resulting solid was dried under vacuum at room temperature and stored for further use.

\subsection{Preparation of PCL, PCL/MCM-48 and PCL/MCM- 48- $\mathrm{NH}_{2} \mathrm{NCs}$ films}

Films of PCL, PCL/MCM-48 and PCL/MCM-48$\mathrm{NH}_{2}$ with $0.5 \%$ concentration of silica NPs relative to the polymer mass were produced. Predetermined amounts of MCM-48 and MCM-48- $\mathrm{NH}_{2}$ nanoparticles were added to $5 \mathrm{~mL}$ of chloroform and sonicated for 30 minutes. A solution of $2.5 \mathrm{~g}$ of PCL with $50 \mathrm{ml}$ of chloroform was then added to this and the mixture stirred for 48 hours. After this step, the sample was poured into a petri dish and the chloroform was removed by evaporation in air at room temperature.

\subsection{Methods and Analysis}

\subsubsection{Irradiation of samples}

All samples were exposed to gamma radiation from a source of ${ }^{60} \mathrm{Cobalt}$ (Gammacell GC220 Excel irradiator - MDS Nordion, Canada) at a dose of $25 \mathrm{kGy}$ (rate of $2.157 \mathrm{kGy} \mathrm{h}^{-1}$, during $11 \mathrm{~h}, 35 \mathrm{~min}$ and $24 \mathrm{~s}$ ), in the presence of air at room temperature. The dose rate in the center of the gammacell irradiator was determined using a Radcal ionization chamber of $0.3 \mathrm{cc}$ volume, previously calibrated in the Ionizing Radiation Metrology Laboratory, located in the Department of Nuclear Energy-Federal University of Pernambuco.

\subsubsection{Fourier Transform Infrared Spectroscopy}

FT-IR spectra was measured with a FT-IR/FT-NIR Perkin Elmer Spectrum 400 Bruker spectrometer in the range of $4000-520 \mathrm{~cm}^{-1}$. Analyses were performed in the attenuated total reflectance mode by direct analysis of samples on $\mathrm{ZnSe}$ crystal.

\subsubsection{X-ray diffraction}

Diffractograms were acquired in a Bruker D8 Advance $\mathrm{X}$-ray diffractometer with $\mathrm{Cu} \mathrm{K} \alpha(0.15 \mathrm{~nm})$, at the speed of $0.02^{\circ} \mathrm{min}^{-1}$ 


\subsubsection{Thermogravimetric analysis}

The thermogravimetric tests were obtained using a SHIMADZU DTG-60H instrument, between room temperature to $600{ }^{\circ} \mathrm{C}$, under nitrogen atmosphere $\left(100 \mathrm{~mL} \cdot \mathrm{min}^{-1}\right)$ at a

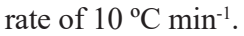

\subsubsection{Differential Scanning Calorimetry}

Heat flow curves were carried out in a differential scanning calorimeter, model 1 Star* system (Mettler Toledo) under a nitrogen atmosphere with the following steps: 1) $0{ }^{\circ} \mathrm{C}$ to $80{ }^{\circ} \mathrm{C}$, at a rate of $10{ }^{\circ} \mathrm{C} \mathrm{min}-1 ; 2$ ) cooling to $0{ }^{\circ} \mathrm{C}$, at a rate of $20^{\circ} \mathrm{C} \mathrm{min}^{-1}$; and 3$) 0^{\circ} \mathrm{C}$ to $80{ }^{\circ} \mathrm{C}$, at a rate of $10{ }^{\circ} \mathrm{C}$ $\min ^{-1[13]}$. The degree of crystallinity $\mathrm{X}_{\mathrm{c}}$ of the films was determined based on the equation: $X_{c}=\frac{\Delta H_{m}}{\Delta H_{m}^{0}}$, where $\Delta H_{m}^{0}$, equals the heat needed for a melting temperature for $100 \%$ crystalline PCL. The value used for the heat of fusion of the fully crystalline polymer was $139.3 \mathrm{~g}-1^{[33]}$.

\subsubsection{Scanning Electron Microscopy (SEM)}

The samples were sputtered on carbon tape on an aluminum support and coated with gold, using a Bal-Tec SCD 050 sputter coater. Images were recorded by a scanning electron microscope (Tescan Mira3) with $10 \mathrm{kV}$ accelerating voltage.

\subsubsection{Transmission Electronic Microscopy (TEM)}

TEM images for the NC films were obtained using a transmission electron microscope (Jeol, model JEM-2100), with $200 \mathrm{kV}$ accelerating voltage. Drops of the NC films suspended in dichloromethane were deposited on copper grids, with slow evaporation of the solvent.

\subsubsection{Mechanical measurements}

Tensile tests were determined on an Instron machine EMIC, DL-500 N, using the ASTM D-882, crosshead speed of $5 \mathrm{~mm} \mathrm{~min}^{-1}$, at room temperature. For the tensile test, three samples of each film were analyzed. Duncan's statistical test was used to identify the presence of significant statistical variations.

\section{Results and Discussions}

\subsection{FT-IR analysis of NCs}

The modification of MCM-48 NPs with the APTES (to obtain a better distribution in the PCL), forms a siloxane bond ${ }^{[34,35]}$ between the APTES and the surface of MCM48 NPs. After modification with the APTES, the NPs and the PCL chain interaction occurs via hydrogen bonds, established with the amine group present in the NPs with the carbonyl groups of the PCL. The characterization of effects of gamma radiation on the structure, mechanical and thermal properties of all films will be presented in the next sections.

FT-IR spectroscopy was used to access the effects of gamma radiation on the chemical structure of films. Figure 1 displays the spectra for MCM-48 NPs and

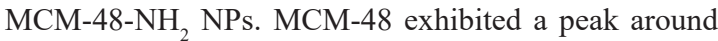

$3430 \mathrm{~cm}^{-1}$, ascribed to Si-OH stretching ${ }^{[35]}$, while the peaks at $1052 \mathrm{~cm}^{-1}$ and $800 \mathrm{~cm}^{-1}$ are related to Si-O-Si asymmetric and symmetric stretching vibration modes ${ }^{[35]}$, respectively. In addition, in MCM-48- $\mathrm{NH}_{2}$, a new peak at $1555 \mathrm{~cm}^{-1}$ can be observed, due to N-H stretching, which suggests the surface modification of MCM-48 NPs with APTES ${ }^{[35]}$.

FT-IR spectra of films are presented in Figure 2. PCL exhibited a peak at $1722 \mathrm{~cm}^{-1}$, ascribed to the carbonyl in the PCL, the peaks at 2948 and $2868 \mathrm{~cm}^{-1}$ originated from the $\mathrm{C}-\mathrm{H}$ bonds of the polymer ${ }^{[36]}$. NCs films exhibited the same spectra of PCL before and after exposure to gamma radiation. In PCL membranes exposed to gamma radiation at $35 \mathrm{kGy}$ and $65 \mathrm{kGy}$, the formation of peaks attributed to $\mathrm{OH}$ (hydroxyl) and $\mathrm{COOH}$ (carboxyl) groups has been observed ${ }^{[30]}$, which is indicative of the radiolytic oxidation of $\mathrm{PCL}^{[37]}$. These findings in general has not been reported for PCL exposed at $25 \mathrm{kGy}^{[29,30]}$. Mallakpour and Khani

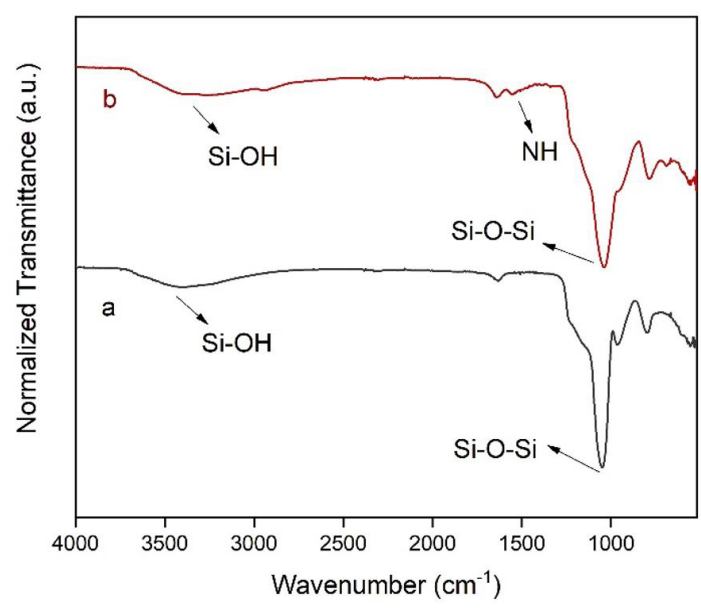

Figure 1. FT-IR spectra of (a) MCM-48 NPs; (b) MCM-48-NH NPs.

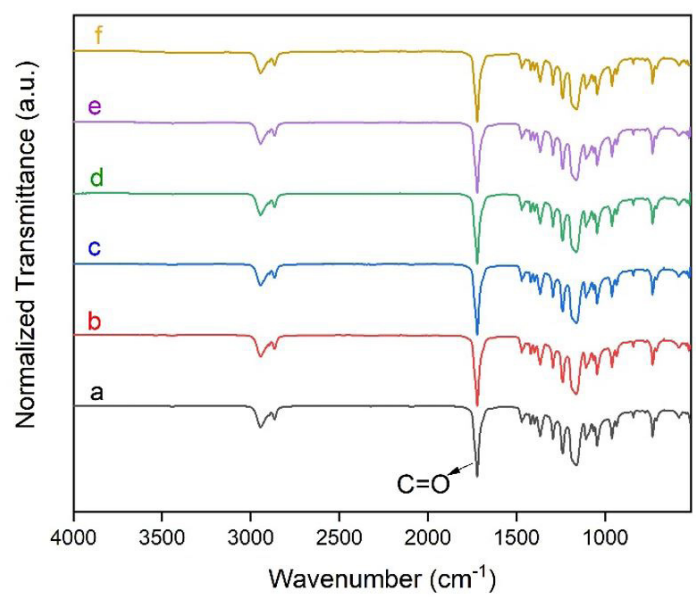

Figure 2. FT-IR spectra of (a) PCL; (b) PCL/MCM-48; (c) PCL/ MCM-48-NH ; (d) PCL-25 kGy; (e) PCL/MCM-48-25 kGy; (f) PCL/MCM-48- $\mathrm{NH}_{2}-25 \mathrm{kGy}$. 
obtained films of NCs formed from PCL with amorphous $\mathrm{SiO}_{2}$ nanoparticles and reported changes in peak position of $\mathrm{C}=\mathrm{O}^{[24]}$. In view of the foregoing, it is possible to state that the chemical structure of the polymer is preserved after the exposure of $\mathrm{PCL}$ and $\mathrm{NC}$ films to gamma radiation at $25 \mathrm{kGy}$.

\subsection{Thermogravimetric analysis}

TGA and its derivative (DTG) curves were acquired to investigate the thermal stability of all samples. Figures $3 a, b$ display the TGA and DTG curves for MCM-48 NPs and MCM-48-NH 2 NPs. The MCM-48 NPs exhibited a mass loss around $100{ }^{\circ} \mathrm{C}$, referring to the loss of water molecules adsorbed on the surface of the material. While the MCM-48- $\mathrm{NH}_{2}$ NPs presented additional mass losses between 200 to $600{ }^{\circ} \mathrm{C}$, ascribed to the decomposition of the organic part, demonstrating the surface modification of MCM-48 NPs with APTES ${ }^{[35]}$.

PCL and NCs films had one event of mass loss, between 200 to $500{ }^{\circ} \mathrm{C}$, as observed in the DTG curves, which was ascribed to the thermal decomposition of the polymer $^{[9,36]}$ (Figures $\left.4 a, b\right)$. Table 1 reports $5 \%\left(\mathrm{~T}_{5}\right), 10 \%$
$\left(\mathrm{T}_{10}\right), 50 \%\left(\mathrm{~T}_{50}\right)$ mass loss temperature for PCL and NCs films and also $\mathrm{T}_{\text {onset }}$ and $\mathrm{T}_{\max }$. Table 1 displays that $\mathrm{T}_{5}$ and $\mathrm{T}_{10}$ of PCL occurred at $361{ }^{\circ} \mathrm{C}$ and $370{ }^{\circ} \mathrm{C}$, respectively, while $\mathrm{T}_{10}$ for PCL/MCM-48- $\mathrm{NH}_{2}$ was $10{ }^{\circ} \mathrm{C}$ higher than PCL. The PCL/MCM-48 had a similar valor for $\mathrm{T}_{10}$ as compared to polymer. $\mathrm{T}_{5}$ exhibited few variations for NCs as compared to PCL matrices. This improvement in the $\mathrm{T}_{10}$ of the polymer in PCL/MCM-48- $\mathrm{NH}_{2}$, can be ascribed by a better distribution of nanoparticles in the PCL due a surface modification of MCM-48 with APTES, which prevented the aggregation of nanoparticles. This stability can be attributed to the interactions between polymers and nanoparticles through the hydrogen bonds formed with groups of NPs with PCL carbonyl groups. Lopes-Figueras and co-workers observed an increase in thermal stability of composites obtained with PCL and MCM-41 nanoparticles modified with EPTES, but these results were observed only in composites with content above $2 \%$ of modified MCM- $41^{[12]}$. PCL and NCs exposed to gamma radiation had the same thermal degradation profile, with similar values for $\mathrm{T}_{5}$ and $\mathrm{T}_{10}$, as compared to the PCL and NCs films before irradiation a)

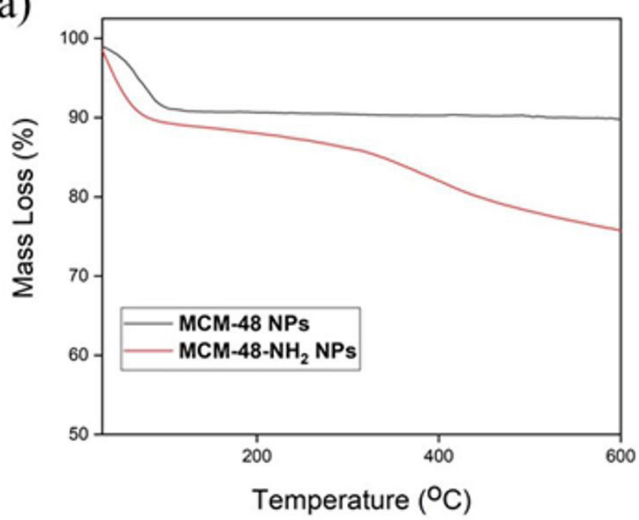

b)

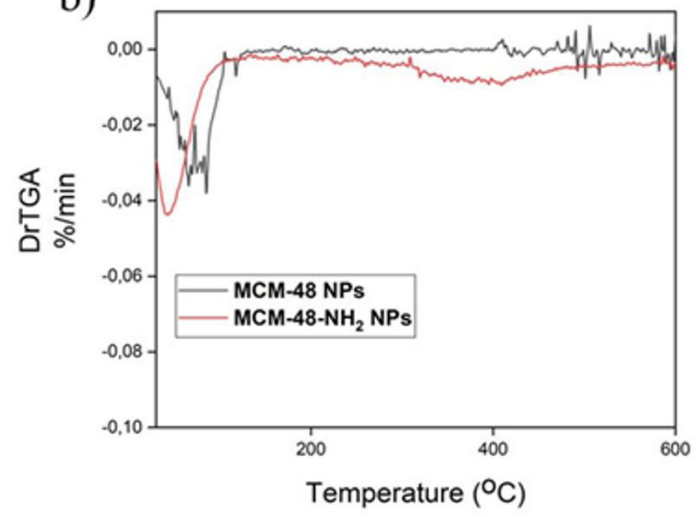

Figure 3. (a) TGA curves of MCM-48 NPs, MCM-48-NH $\mathrm{N}_{2}$ NP; (b) DTG curves of MCM-48 NPs, MCM-48-NH 2 NPs.

a)

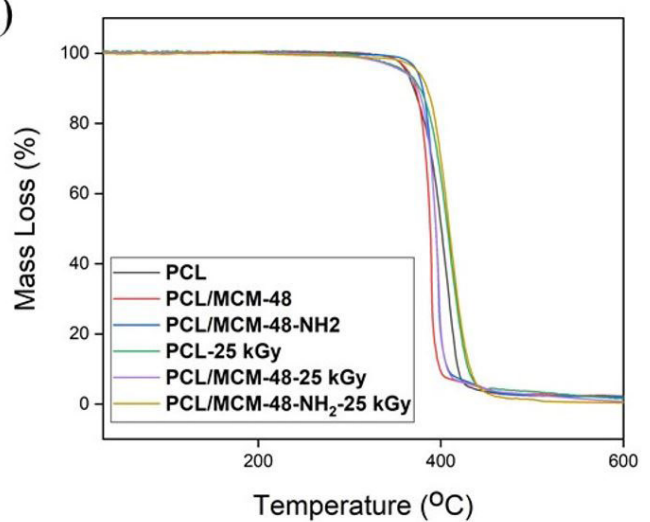

b)

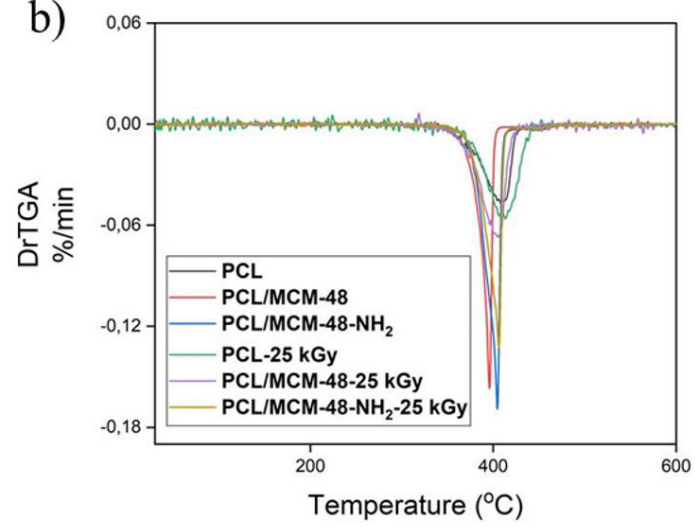

Figure 4. (a) TGA curves of PCL, PCL/MCM-48, PCL/MCM-48-NH ${ }_{2}$ PCL-25 kGy, PCL/MCM-48-25 kGy, PCL/MCM-48-NH -25 kGy; (b) DTG curves of PCL, PCL/MCM-48, PCL/MCM-48-NH, PCL-25 kGy, PCL/MCM-48-25 kGy, PCL/MCM-48-NH -25 kGy. 
(Figure 4a). In another study different from our results Lyu and co-workers found 3 mass loss events for composite films formed by PCL with grapefruit seed extract, this thermal behavior profile was attributed to the characteristic of the grapefruit seed extract used to obtain the films ${ }^{[38]}$. These results indicate that gamma radiation did not change the thermal properties of PCL and its NCs films.

\subsection{X-ray diffraction patterns}

$\mathrm{X}$-Ray diffraction was used to determine the crystalline profile of NPs and NCs before and after exposure to gamma radiation. Figure 5 shows the diffractograms for NPs. The peak observed for MCM-48 NPs at $2.6^{\circ}$ is attributed to plane (211), characteristic of the spatial group Ia $3 d$ of the cubic structure of silica ${ }^{[23,35,39]}$. The diffractogram for MCM-48- $\mathrm{NH}_{2} \mathrm{NPs}$ exhibited one reflection angle, indicating that the structure of the silica had been preserved ${ }^{[35]}$ (Figure 5). The intensity of the diffractogram for modified NPs decreased, which may be due to the organic groups on silica after modification with APTES ${ }^{[35]}$.

The PCL has three reflections at $21.5^{\circ}, 22^{\circ}$ and $23.8^{\circ}$, relative to (110), (111) and (200) planes, respectively, of the orthorhombic crystal structure of PCL ${ }^{[40]}$ (Figure 6). NCs films showed only the semi-crystalline behavior of PCL. The same results were observed for the PCL and NCs films after exposure to gamma radiation (Figure 6), indicating that the gamma radiation at $25 \mathrm{kGy}$ had preserved the crystalline structure of polymer ${ }^{[30]}$.

\subsection{Differential Scanning Calorimetry (DSC)}

DSC analyses were conducted to access the crystallinity of PCL, PCL/MCM-48 and PCL/MCM-48-NH . Table 2 presents the values for $\mathrm{T}_{\mathrm{m}}$ (melting temperature), $\mathrm{T}_{\mathrm{c}}$ (crystallization temperature), $\Delta \mathrm{H}_{\mathrm{m}}$ (melt enthalpy) and $\mathrm{X}_{\mathrm{c}}$ (crystallinity percentage) for all films analyzed. Addition of MCM48 NPs modified with APTES increased the $\mathrm{T}_{\mathrm{m}}$ of the PCL to $65.70{ }^{\circ} \mathrm{C}$, with the same behavior being verified for the $\mathrm{T}_{\mathrm{m}}$ of PCL/MCM-48-NH$-25 \mathrm{kGy}$. The results for $\mathrm{T}_{\mathrm{m}}$ obtained by DSC indicate that the addition of NPs and the subsequent gamma radiation exposure of the NCs films did not significantly alter the crystalline structure of the PCL in the irradiated films, as observed in the section on X-ray diffraction (Section 3.3) also identified by Horacova and

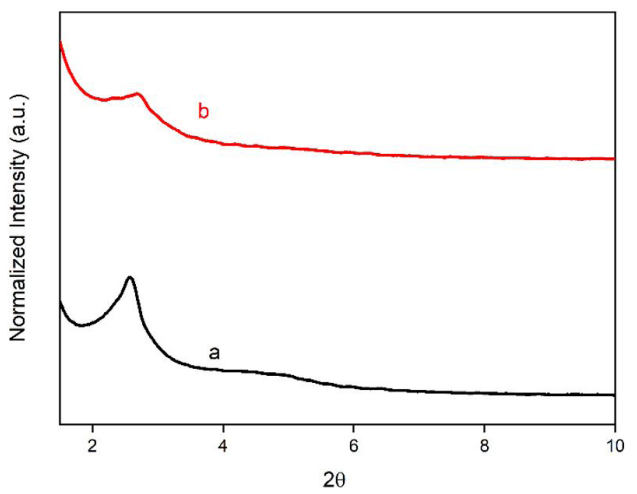

'Figure 5. XRD curves of (a) MCM-48 NPs; (b) MCM-48- $\mathrm{NH}_{2}$ NPs.

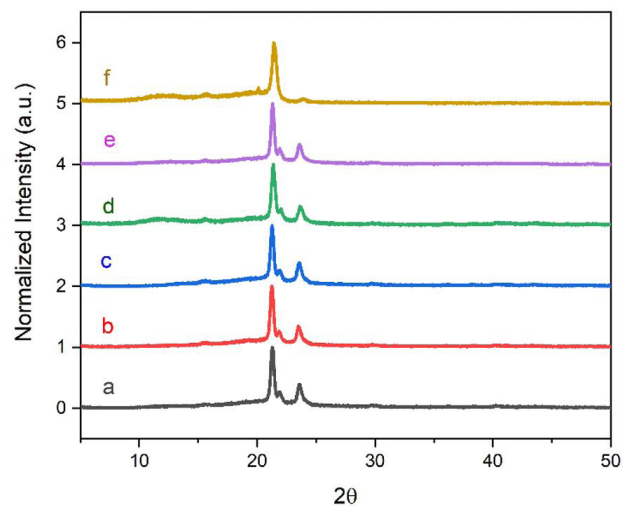

Figure 6. XRD curves of (a) PCL; (b) PCL/MCM-48; (c) PCL/MCM-48-NH; ; (d) PCL-25 kGy; (e) PCL/MCM-48-25 kGy; (f) PCL/MCM-48- $\mathrm{NH}_{2}-25 \mathrm{kGy}$.

Table 1. Thermal properties of PCL, PCL/MCM-48, PCL/MCM-48- $\mathrm{NH}_{2}$ NCs films before and after irradiated at $25 \mathrm{kGy}$.

\begin{tabular}{cccccc}
\hline Sample & $\mathbf{T}_{\mathbf{5}}\left({ }^{\circ} \mathbf{C}\right)$ & $\mathbf{T}_{\mathbf{1 0}}\left({ }^{\circ} \mathbf{C}\right)$ & $\mathbf{T}_{\mathbf{5 0}}\left({ }^{\circ} \mathbf{C}\right)$ & $\mathbf{T}_{\text {onset }}\left({ }^{\circ} \mathbf{C}\right)$ & $\mathbf{T}_{\max }\left({ }^{\circ} \mathbf{C}\right)$ \\
\hline PCL & 361 & 370 & 401 & 381 & 408 \\
PCL/MCM-48 & 364 & 372 & 388 & 385 & 397 \\
PCL/MCM-48-NH & 374 & 380 & 395 & 389 & 399 \\
PCL-25 kGy & 359 & 377 & 408 & 389 & 409 \\
PCL/MCM-48-25 kGy & 357 & 374 & 394 & 389 & 405 \\
PCL/MCM-48-NH $-25 \mathrm{kGy}$ & 374 & 385 & 409 & 390 & 407 \\
\hline
\end{tabular}

Table 2. Melting temperature, crystallization temperature, enthalpy of melting and percentage of crystallinity for PCL, PCL/MCM-48, and PCL/MCM-48- $\mathrm{NH}_{2} \mathrm{NCs}$ films before and after irradiated at $25 \mathrm{kGy}$.

\begin{tabular}{ccccc}
\hline Sample & $\mathbf{T}_{\mathbf{m}}\left({ }^{\mathbf{C}}\right)$ & $\mathbf{T}_{\mathbf{c}}\left({ }^{(} \mathbf{C}\right)$ & $\Delta \mathbf{H}_{\mathbf{m}}(\mathbf{J} / \mathbf{g})$ & $\mathbf{X}_{\mathbf{c}}(\mathbf{\%})$ \\
\hline PCL & 61.33 & 20.46 & 61.14 & 43.89 \\
PCL/MCM-48 & 61.40 & 22.80 & 29.34 & 21.06 \\
PCL/MCM-48-NH & 65.70 & 23.42 & 49.69 & 35.67 \\
PCL-25 kGy & 61.91 & 23.46 & 44.82 & 32.18 \\
PCL/MCM-48-25 kGy & 56.46 & 20.64 & 37.15 & 26.67 \\
PCL/MCM-48-NH $-25 \mathrm{kGy}$ & 65.85 & 23.00 & 51.78 & 37.18 \\
\hline
\end{tabular}


co-workers ${ }^{[41]}$. The increase in $\mathrm{T}_{\mathrm{m}}$ for NCs with modified NPs may be assigned to the wide dispersion of the NPs in the PCL, which facilitates the generation of thick crystals, which does not occur with unmodified NPs ${ }^{[42]}$. The crystallization temperature of PCL in the films increased with the addition of NPs. For irradiated samples, marginal variations were observed in $\mathrm{T}_{c}$. The crystallinity content of PCL (43.89\%) is in accordance with the reported ${ }^{[13,43]}$. For the irradiated PCL and PCL/MCM-48-25 kGy films, however, a reduction in the crystallinity content was observed. These results agree with the findings reported by Foggia and co-workers where they found that gamma radiation did not cause major changes in crystallinity and composition on biomedical poly-(e-caprolactone)/hydroxyapatite composites ${ }^{[4]}$. These findings indicate that the exposure of the PCL and NCs films to gamma radiation at $25 \mathrm{kGy}$ did not produce significant changes in Tm, Tc and Xc for the analyzed samples.

\subsection{Scanning Electron Microscopy (SEM)}

The surface morphology of PCL and NCs films was evaluated by SEM analysis. Figure 7a shows the smooth surface of PCL. Figures 7b, c show the surface and cross-section morphology of PCL/MCM-48 and PCL/PCL-48-NH 2 NCs films, respectively, where the images revealed that spherical NPs were randomly distributed on the PCL. Figure 8 shows that the surface morphology of nancomposite films irradiated at $25 \mathrm{kgy}$ is preserved.
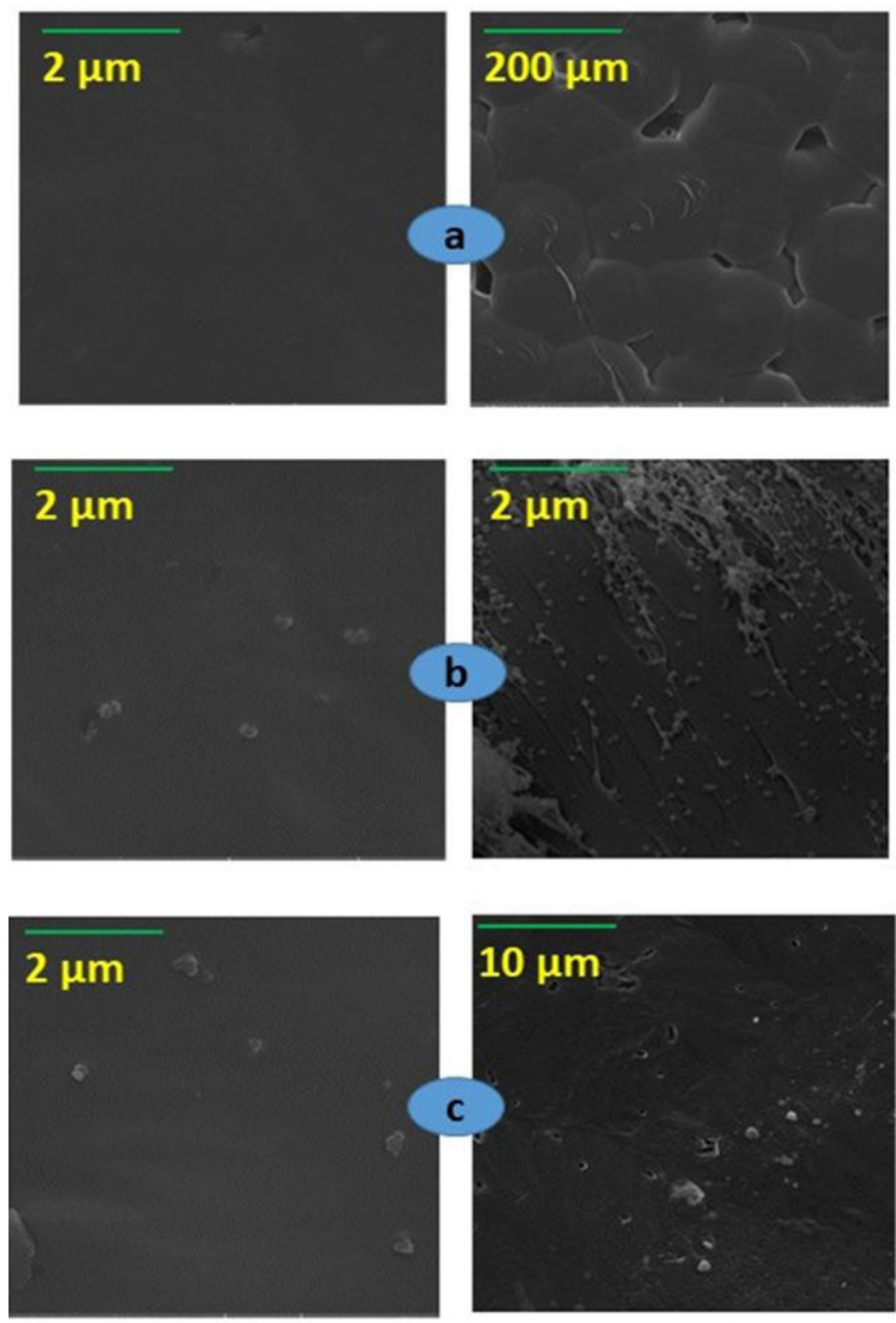

Figure 7. SEM images of (a) surface of PCL; (b) surface (left) and cross-section of PCL/MCM-48 (right); (c) surface (left) and cross-section (right) of PCL-MCM-48- $\mathrm{NH}_{2}$. 


\subsection{Transmission Electron Microscopy (TEM)}

Figure 9a, b exhibit the TEM images for the PCL/MCM-48 and PCL/MCM-48-NH films, histograms for NPs size distribution and the mean value of the NPs in the films. The images obtained by TEM revealed that

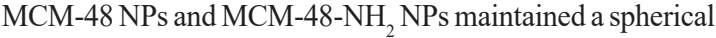
shape and random dispersion in the PCL. The mean particle size calculated for MCM-48 NPs and MCM-48-NH 2 NPs on the films was $171.2 \mathrm{~nm}$ and $148.6 \mathrm{~nm}$, respectively. NPs modified with APTES showed a reduction around $20 \mathrm{~nm}$ for the mean particle size. This reduction was attributed to the alteration of the NPs with APTES, which reduced the aggregation of the NPs and favored their interaction with the polymer, reducing the aggregation of NPs in the PCL ${ }^{[24]}$.

\subsection{Mechanical properties}

The mechanical properties of PCL, PCL/MCM-48 and PCL/MCM-48- $\mathrm{NH}_{2}$ films are shown in Table 3. The parameters evaluated were tensile strength $(\sigma)$, modulus of elasticity $(\varepsilon)$ and elongation at break $(\mathrm{Eb})$. The mean values were compared by the Duncan test, with a significance level of $5 \%$. The Duncan test found that the tensile strength for irradiated and non-irradiated NC films did not have significant statistical differences. Duncan's test also did not observe statistically significant variations for the modulus of elasticity for all samples analyzed. However, Duncan's test indicated an increase in Eb for samples PCL/MCM48 and PCL/MCM-48- $\mathrm{NH}_{2}$, which is consistent with the literature ${ }^{[12,24,45]}$. The improvement in the mean $\mathrm{Eb}$ value

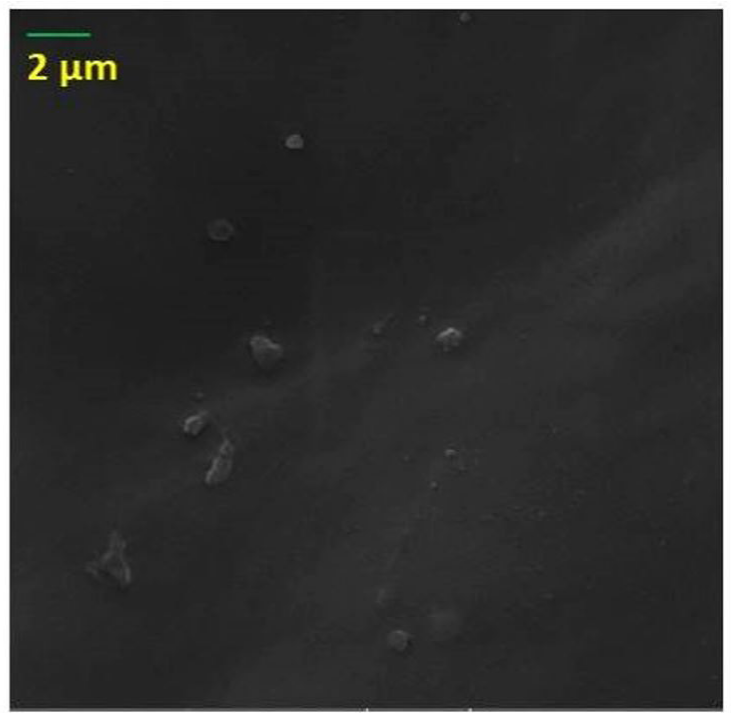

Figure 8. SEM images of surface of PCL/MCM-48-25 kGy (left) and ) PCL/MCM-48- $\mathrm{NH}_{2}-25 \mathrm{kGy}$ (right).
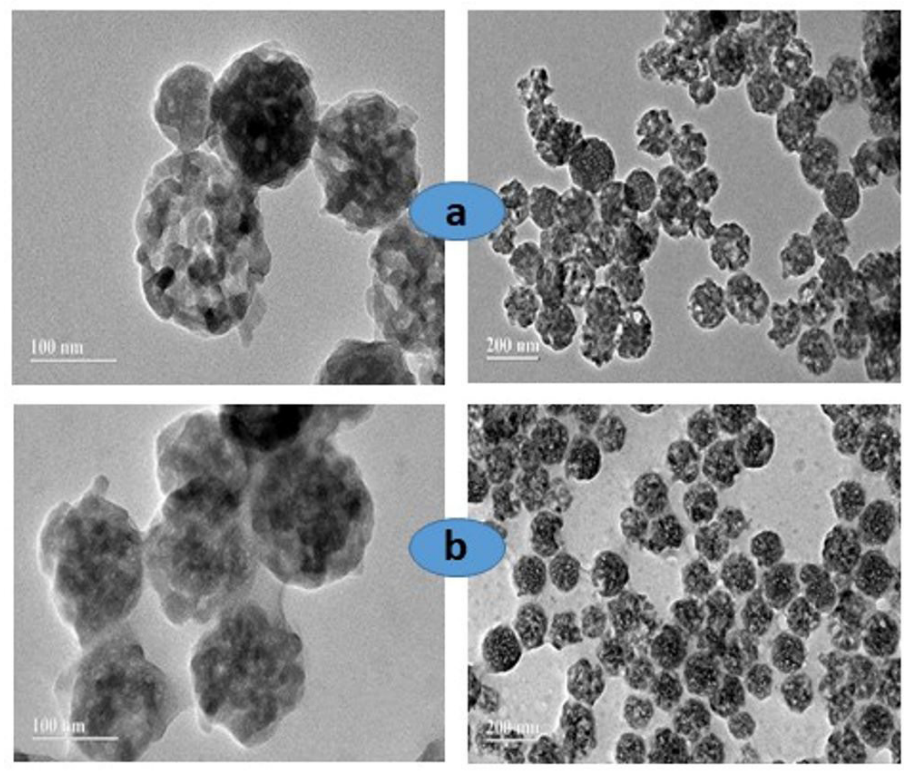

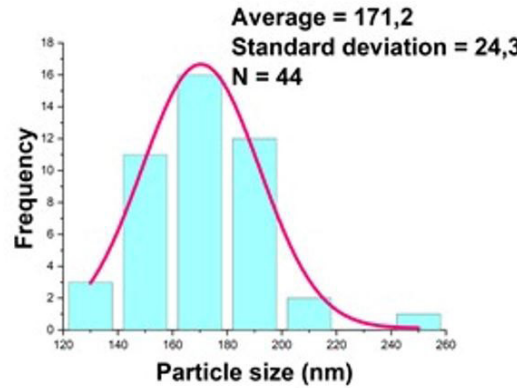

Average $=148,6$

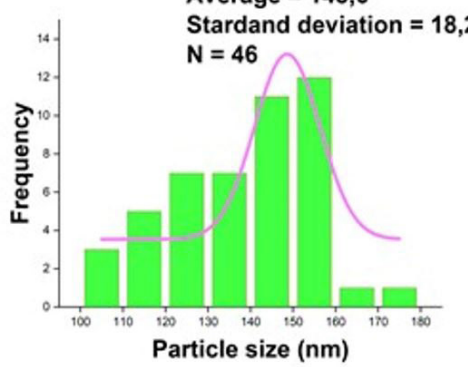

Figure 9. TEM images of (a) PCL/MCM-48; (b) PCL/MCM-48- $\mathrm{NH}_{2}$. 
Paula, M. V., Azevedo, L. A., Silva, I. D. L., Vinhas, G. M., \& Alves Junior, S.

Table 3. Mechanical properties obtained for PCL, PCL/MCM-48, PCL/MCM-48- $\mathrm{NH}_{2}$ NCs films before and afterirradiation at $25 \mathrm{kGy}$.

\begin{tabular}{|c|c|c|c|}
\hline Sample & $\sigma(\mathrm{MPa})$ & $\varepsilon(\mathrm{MPa})$ & $\operatorname{Eb}(\%)$ \\
\hline PCL & $10.18 \pm 0.62^{\mathrm{a}}$ & $169.86 \pm 7.01^{\mathrm{a}}$ & $76.29 \pm 5.79^{\mathrm{a}}$ \\
\hline PCL/MCM-48 & $9.98 \pm 1.15^{\mathrm{a}}$ & $174.36 \pm 9.58^{\mathrm{a}}$ & $376,70 \pm 9.04^{b}$ \\
\hline PCL/MCM-48-NH ${ }_{2}$ & $9.28 \pm 0.76^{\mathrm{a}}$ & $170.30 \pm 9.26^{\mathrm{a}}$ & $137,40 \pm 15.51^{\mathrm{c}}$ \\
\hline PCL-25 kGy & $10.34 \pm 1.17^{\mathrm{a}}$ & $167.70 \pm 9.98^{\mathrm{a}}$ & $44,55 \pm 0.98^{d}$ \\
\hline PCL/MCM-48-25 kGy & $9.38 \pm 0.97^{\mathrm{a}}$ & $164.16 \pm 4.06^{\mathrm{a}}$ & $123,63 \pm 9.51^{\mathrm{c}}$ \\
\hline PCL/MCM-48-NH -25 kGy & $9.21 \pm 1.43^{\mathrm{a}}$ & $182.2 \pm 17.02^{\mathrm{a}}$ & $50,72 \pm 7,71^{\mathrm{d}}$ \\
\hline
\end{tabular}

The mean with the same letter (i.e. a) in the same column did not differ at $\mathrm{p}<0.05$ for the Duncan's test.

of these samples is attributed to the formation of hydrogen bonds between the MCM-48 and the PCL chains, favoring the interfacial adhesion between the components of the nanocomposites ${ }^{[24]}$. The reduction of $\mathrm{Eb}$ in the irradiated samples is attributed to the effects of gamma radiation on the films. These results indicate that gamma radiation at $25 \mathrm{kGy}$ did not modify the mechanical properties of tensile strength and modulus of elasticity of PCL and NCs films. This indicates that the use of gamma radiation at $25 \mathrm{kGy}$ is a suitable method for the sterilization of the nanocomposite films formed by PCL with MCM-48 NPs modified with APTES.

\section{Conclusions}

PCL nanocomposites films with $0.5 \%$ of MCM-48 and MCM-48- $\mathrm{NH}_{2}$ NPs, were satisfactorily obtained by the solvent evaporation method and exposed to gamma radiation at $25 \mathrm{kGy}$. The images obtained by MEV and TEM revealed the presence of aggregates of NPs randomly dispersed in the films. TEM images exhibited that the MCM-48- $\mathrm{NH}_{2} \mathrm{NPs}$ presented smaller particle size in the PCL, which was attributed to modification with the APTES. Samples irradiated at $25 \mathrm{kGy}$ had the same spectral behavior in the infrared region as the non-irradiated samples, which is indicative of the maintenance of the chemical structure of the PCL. The same results were observed in the diffractograms of the irradiated films, indicating the maintenance of the semicrystalline character of PCL. The PCL MCM-48-NH film exhibited an enhancement to the thermal stability of PCL, due to modification with the APTES. The exposure of the

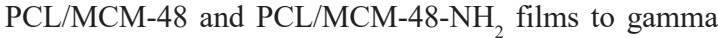
radiation at $25 \mathrm{kGy}$ did not cause major changes in the mechanical and thermal properties of NC films, demonstrating success of the sterilization method.

\section{Acknowledgements}

The authors thank Fundação de Amparo Ciência e Tecnologia do Estado de Pernambuco (FACEPE) for the provided scholarships.

\section{References}

1. Labet, M., \& Thielemans, W. (2009). Synthesis of polycaprolactone: a review. Chemical Society Reviews, 38(12), 3484-3504. http:// dx.doi.org/10.1039/b820162p. PMid:20449064.

2. Woodruff, M. A., \& Hutmacher, D. W. (2010). The return of a forgotten polymer Polycaprolactone in the 21 st century.
Progress in Polymer Science, 35(10), 1217-1256. http://dx.doi. org/10.1016/j.progpolymsci.2010.04.002.

3. Pêgo, A. P., Poot, A. A., Grijpma, D. W., \& Feijen, J. (2001). Copolymers of trimethylene carbonate and epsilon-caprolactone for porous nerve guides: synthesis and properties. Journal of Biomaterials Science. Polymer Edition, 12(1), 35-53. http:// dx.doi.org/10.1163/156856201744434. PMid:11334188.

4. Moraczewski, K., Stepczyńska, M., Malinowski, R., Rytlewski, P., Jagodziński, B., \& Zenkiewicz, M. (2016). Stability studies of plasma modification effects of polylactide and polycaprolactone surface layers. Applied Surface Science, 377, 228-237. http:// dx.doi.org/10.1016/j.apsusc.2016.03.171.

5. Bhagabati, P., Das, D., \& Katiyar, V. (2021). Bamboo-flourfilled cost-effective poly(e-caprolactone) biocomposites: a potential contender for flexible cryo-packaging applications. Materials Advances, 2(1), 280-291. http://dx.doi.org/10.1039/ D0MA00517G.

6. Carvalho, J. R. G., Conde, G., Antonioli, M. L., Dias, P. P., Vasconcelos, R. O., Taboga, S. R., Canola, P. A., Chinelatto, M. A., Pereira, G. T., \& Ferraz, G. C. (2020). Biocompatibility and biodegradation of poly(lactic acid) (PLA) and an immiscible PLA/poly( $\varepsilon$-caprolactone) (PCL) blend compatibilized by poly( $\varepsilon$-caprolactone-b-tetrahydrofuran) implanted in horses. Polymer Journal, 52(6), 629-643. http://dx.doi.org/10.1038/ s41428-020-0308-y.

7. Stewart, S. A., Domínguez-Robles, J., McIlorum, V. J., Gonzalez, Z., Utomo, E., Mancuso, E., Lamprou, D. A., Donnelly, R. F., \& Larrañeta, E. (2020). Poly(caprolactone)based coatings on 3D-printed biodegradable implants: a novel strategy to prolong delivery of hydrophilic drugs. Molecular Pharmaceutics, 17(9), 3487-3500. http://dx.doi.org/10.1021/ acs.molpharmaceut.0c00515. PMid:32672976.

8. Abudula, T., Gauthaman, K., Mostafavi, A., Alshahrie, A., Salah, N., Morganti, P., Chianese, A., Tamayol, A., \& Memic, A. (2020). Sustainable drug release from polycaprolactone coated chitin lignin gel fibrous scaffolds. Scientific Reports, 10(1), 20428. http://dx.doi.org/10.1038/s41598-020-76971-w. PMid:33235239.

9. Zimmerling, A., Yazdanpanah, Z., Cooper, D. M. L., Johnston, J. D., \& Chen, X. (2021). 3D printing PCL / nHA bone scaffolds: exploring the influence of material synthesis techniques. Biomaterials Research, 25(1), 3. http://dx.doi.org/10.1186/ s40824-021-00204-y. PMid:33499957.

10. Gutiérrez, T. J., Mendieta, J. R., \& Ortega-Toro, R. (2021). In-depth study from gluten/PCL-based food packaging films obtained under reactive extrusion conditions using chrome octanoate as a potential food grade catalyst. Food Hydrocolloids, 111, 106255. http://dx.doi.org/10.1016/j.foodhyd.2020.106255.

11. Shi, K., Jing, J., Song, L., Su, T., \& Wang, Z. (2020). Enzymatic hydrolysis of polyester: degradation of poly( $\varepsilon$ - caprolactone) by Candida antarctica lipase and Fusarium solani cutinase. International Journal of Biological Macromolecules, 144, 183-189. http://dx.doi.org/10.1016/j.ijbiomac.2019.12.105. PMid:31843602. 
12. Lopez-Figueras, L., Navascues, N., \& Irusta, S. (2017). Polycaprolactone/mesoporous silica MCM-41 composites prepared by in situ polymerization. Particuology, 30, 135-143. http://dx.doi.org/10.1016/j.partic.2016.05.005.

13. Elen, K., Murariu, M., Peeters, R., Dubois, P., Mullens, J., Hardy, A., \& Van Bael, M. K. (2012). Towards high-performance biopackaging: barrier and mechanical properties of dual-action polycaprolactone/zinc oxide nanocomposites. Polymers for Advanced Technologies, 23(10), 1422-1428. http://dx.doi. org/10.1002/pat.2062.

14. Gautam, S., Sharma, C., Purohit, S. D., Singh, H., Dinda, A. K., Potdar, P. D., Chou, C., \& Mishra, N. C. (2021). Gelatinpolycaprolactone-nanohydroxyapatite electrospun nanocomposite scaffold for bone tissue engineering. Materials Science and Engineering C, 119, 111588. http://dx.doi.org/10.1016/j. msec.2020.111588. PMid:33321633.

15. Mallakpour, S., \& Madani, M. (2015). A review of current coupling agents for modification of metal oxide nanoparticles. Progress in Organic Coatings, 86, 194-207. http://dx.doi. org/10.1016/j.porgcoat.2015.05.023.

16. Griffin, M., Nayyer, L., Butler, P. E., Palgrave, R. G., Seifalian, A. M., \& Kalaskar, D. M. (2016). Development of mechanoresponsive polymeric scaffolds using functionalized silica nano-fillers for the control of cellular functions. Nanomedicine; Nanotechnology, Biology, and Medicine, 12(6), 1725-1733. http://dx.doi.org/10.1016/j.nano.2016.02.011. PMid:27013128.

17. Guo, Y., Yan, L., Zeng, Z., Chen, L., Ma, M., Luo, R., Bian, J., Lin, H., \& Chen, D. (2020). PU/PLA nanocomposites with improved mechanical and shape memory properties fabricated via phase morphology control and incorporation of multiwalled carbon nanotubes nanofillers. Polymer Engineering and Science, 60(6), 1118-1128. http://dx.doi.org/10.1002/ pen. 25365 .

18. Mallakpour, S., Abdolmaleki, A., \& Moosavi, S. E. (2015). A green route for the synthesis of alanine-based Poly (amideimide) nanocomposites reinforced with the modified $\mathrm{ZnO}$ by Poly (vinyl alcohol) as a Biocompatible Coupling Agent. Polymer-Plastics Technology and Engineering, 54(14), 14481456. http://dx.doi.org/10.1080/03602559.2014.996907.

19. Schumacher, K., Grün, M., \& Unger, K. K. (1999). Novel synthesis of spherical MCM-48. Microporous and Mesoporous Materials, 27(2-3), 201-206. http://dx.doi.org/10.1016/S13871811(98)00254-6.

20. Zhang, F., Lee, D., \& Pinnavaia, T. J. (2010). PMMA/mesoporous silica nanocomposites: effect of framework structure and pore size on thermomechanical properties. Polymer Chemistry, 1(1), 107-113. http://dx.doi.org/10.1039/B9PY00232D.

21. Kim, T., Chung, P., \& Lin, V. S. (2010). Facile synthesis of monodisperse spherical MCM-48 mesoporous silica nanoparticles with controlled particle size. Chemistry of Materials, 22(17), 5093-5104. http://dx.doi.org/10.1021/cm1017344.

22. Shen, J. L., Lee, Y. C., Liu, Y. L., Yu, C. C., Cheng, P. W., \& Cheng, C. F. (2003). Photoluminescence sites on MCM-48. Microporous and Mesoporous Materials, 64(1-3), 135-143. http://dx.doi.org/10.1016/j.micromeso.2003.08.001.

23. Schumacher, K., Ravikovitch, P. I., Chesne, A., Neimark, A. V., \& Unger, K. K. (2000). Characterization of MCM48 Materials. Langmuir, 16(10), 4648-4654. http://dx.doi. org/10.1021/la991595i.

24. Mallakpour, S., \& Khani, Z. (2018). Surface modified SiO2 nanoparticles by thiamine and ultrasonication synthesis of PCL/SiO2-VB1 NCs: Morphology, thermal, mechanical and bioactivity investigations. Ultrasonics Sonochemistry, 41, 527-537. http://dx.doi.org/10.1016/j.ultsonch.2017.10.015. PMid:29137784.
25. Coombes, A. G. A., Rizzi, S. C., Williamson, M., Barralet, J. E., Downes, S., \& Wallace, W. A. (2004). Precipitation casting of polycaprolactone for applications in tissue engineering and drug delivery. Biomaterials, 25(2), 315-325. http://dx.doi. org/10.1016/S0142-9612(03)00535-0. PMid:14585719.

26. Yang, L., Li, J., Jin, Y., Li, M., \& Gu, Z. (2015). In vitro enzymatic degradation of the cross-linked poly( $\varepsilon$-caprolactone) implants. Polymer Degradation \& Stability, 112, 10-19. http:// dx.doi.org/10.1016/j.polymdegradstab.2014.12.008.

27. Kweon, H., Yoo, M. K., Park, I. K., Kim, T. H., Lee, H. C., Lee, H., Oh, J., Akaike, T., \& Cho, C. (2003). A novel degradable polycaprolactone networks for tissue engineering. Biomaterials, 24(5), 801-808. http://dx.doi.org/10.1016/S01429612(02)00370-8. PMid:12485798.

28. Rešček, A., Katančić, Z., Krehula, L. K., Ščetar, M., HrnjakMurgić, Z., \& Galić, K. (2018). Development of double-layered PE/PCL films for food packaging modified with zeolite and magnetite nanoparticles. Advances in Polymer Technology, 37(3), 837-842. http://dx.doi.org/10.1002/adv.21727.

29. Bosworth, L. A., Gibb, A., \& Downes, S. (2012). Gamma irradiation of electrospun poly( $\varepsilon$-caprolactone) fibers affects material properties but not cell response. Journal of Polymer Science. Part B, Polymer Physics, 50(12), 870-876. http:// dx.doi.org/10.1002/polb.23072.

30. Augustine, R., Saha, A., Jayachandran, V. P., Thomas, S., \& Kalarikkal, N. (2015). Dose dependent effects of gamma irradiation on the materials properties and cell proliferation of electrospun polycaprolactone tissue engineering scaffolds. International Journal of Polymeric Materials and Polymeric Biomaterials, 64(10), 526-533. http://dx.doi.org/10.1080/00 914037.2014.977900.

31. Aquino, K. A. S. (2012). Sterilization by gamma irradiation. In F. Adrovic (Ed.), Gamma irradiation (pp. 171-206). Croatia: Intech. http://dx.doi.org/10.5772/34901.

32. Zhang, L., Yu, C., Zhao, W., Hua, Z., Chen, H., Li, L., \& Shi, J. (2007). Preparation of multi-amine-grafted mesoporous silicas and their application to heavy metal ions adsorption. Journal of Non-Crystalline Solids, 353(44-46), 4055-4061. http://dx.doi.org/10.1016/j.jnoncrysol.2007.06.018.

33. Koenig, M. F., \& Huang, S. J. (1995). Biodegradable blends and composites of polycaprolactone and starch derivatives. Polymer, 36(9), 1877-1882. http://dx.doi.org/10.1016/00323861(95)90934-T.

34. Nawrocki, J. (1997). The silanol group and its role in liquid chromatography. Journal of Chromatography. A, 779(1-2), 29-71. http://dx.doi.org/10.1016/S0021-9673(97)00479-2.

35. Bahrami, Z., Badiei, A., \& Atyabi, F. (2014). Surface functionalization of SBA-15 nanorods for anticancer drug delivery. Chemical Engineering Research \& Design, 92(7), 1296-1303. http://dx.doi.org/10.1016/j.cherd.2013.11.007.

36. Mallakpour, S., \& Nouruzi, N. (2016). Effect of modified $\mathrm{ZnO}$ nanoparticles with biosafe molecule on the morphology and physiochemical properties of novel polycaprolactone nanocomposites. Polymer, 89, 94-101. http://dx.doi.org/10.1016/j. polymer.2016.02.038.

37. Kornacka, E. M. (2017). Radiation-induced oxidation of polymers. In Y. Sun, \& A. Chmielewski (Eds.), Applications of ionizing radiation in materials processing (pp. 183-192). Warszawa: Institute of Nuclear Chemistry and Technology, Erasmus.

38. Lyu, J. S., Lee, J., \& Han, J. (2019). Development of a biodegradable polycaprolactone film incorporated with an antimicrobial agent via an extrusion process. Scientific Reports, 9(1), 20236. http://dx.doi.org/10.1038/s41598-019-56757-5. PMid:31882928. 
39. Solovyov, L. A., Belousov, O. V., Dinnebier, R. E., Shmakov, A. N., \& Kirik, S. D. (2007). X-ray diffraction structure analysis of MCM-48 mesoporous silica. The Journal of Physical Chemistry B, 109(8), 3233-3237. http://dx.doi.org/10.1021/ jp068521h. PMid:16851346.

40. Augustine, R., Malik, H. N., Singhal, D. K., Mukherjee, A., Malakar, D., Kalarikkal, N., \& Thomas, S. (2014). Electrospun polycaprolactone/ $\mathrm{ZnO}$ nanocomposite membranes as biomaterials with antibacterial and cell adhesion properties. Journal of Polymer Research, 21(3), 347. http://dx.doi.org/10.1007/ s10965-013-0347-6.

41. Horakova, J., Klicova, M., Erben, J., Klapstova, A., Novotny, V., Behalek, L., \& Chvojka, J. (2020). Impact of Various Sterilization and Disinfection Techniques on Electrospun Poly- $\varepsilon$-caprolactone. ACS Omega, 5(15), 8885-8892. http:// dx.doi.org/10.1021/acsomega.0c00503. PMid:32337451.

42. Augustine, R., Kalarikkal, N., \& Thomas, S. (2016). Effect of zinc oxide nanoparticles on the in vitro degradation of electrospun polycaprolactone membranes in simulated body fluid. International Journal of Polymeric Materials and
Polymeric Biomaterials, 65(1), 28-37. http://dx.doi.org/10.1 080/00914037.2015.1055628.

43. Kostakova, E. K., Meszaros, L., Maskova, G., Blazkova, L., Turcsan, T., \& Lukas, D. (2017). Crystallinity of Electrospun and Centrifugal Spun Polycaprolactone Fibers: A Comparative Study. Journal of Nanomaterials, 2017, 8952390. http://dx.doi. org/10.1155/2017/8952390.

44. Foggia, M., Corda, U., Plescia, E., Taddei, P., \& Torreggiani, A. (2010). Effects of sterilisation by high-energy radiation on biomedical poly-(e-caprolactone)/hydroxyapatite composites. Journal of Materials Science. Materials in Medicine, 21(6), 1789-1797. http://dx.doi.org/10.1007/s10856-010-4046-0. PMid:20224934.

45. Leonés, A., Mujica-Garcia, A., Arrieta, M. P., Salaris, V., Lopez, D., Kenny, J. M., \& Peponi, L. (2020). Organic and inorganic PCL-based elesctospun fibers. Polymers, 12(6), 1325. http:// dx.doi.org/10.3390/polym12061325. PMid:32532052.

Received: June 02, 2021

Revised: Oct. 24, 2021

Accepted: Oct. 28, 2021 